\title{
用行为导向法培养中职学生机械基础课程的自主学习能力
}

覃佐知

常德财经中等专业学校

DOI:10.32629/jief.v2i11.2548

[摘 要] 行为导向，又称作行动导向或者实践导向，是由多种教学手段、方法、技术整合而成。在中职机械基础课程的教学中，教师以行为 导向法为指导, 通过学生的行为变化来不断改变教学目标和教学任务, 引导学生建立起自主学习的能力。自主学习能力对学生来说非常重要, 拥有优秀的自主学习能力, 除了会提升学习成绩外，对学生日后的发展都有着一定的影响。基于此，本文首先指出了中职教学中存在的问题， 接下来提出几点通过行为导向法培养中职学生机械基础课程自学能力的策略, 以期为中职教育工作者提供一定的帮助与参考。

[关键词] 行为导向; 中职教育; 机械基础; 自主学习; 策略

中图分类号：G633 文献标识码：A

机械基础课程对于中职一、二年级的学生来说具有较大的难度, 学 生在学习过程中不仅会遇到一定的阻碍, 还会因为学习困难造成不愿意 去主动学习的现象, 如果教师不改变以往传统的教学方式、方法, 仍然 采用 “灌输式” 的教学模式, 那么久而久之学生将对机械基础课程产生 排斥心理。因此, 在课程进行过程中, 教师可采用行为导向法培养中职 学生的自主学习能力, 帮助学生建立起一定的空间想象能力, 更好的进 行机械基础课程的学习。

\section{1 行为导向教学模式的基本含义}

行为导向法是现代职业教育中应用的一种新式教学方法, 在行为导 向法中教师起到了 “引导者” 的作用, 其目的在于突破以往传统的教学 思想, 改变学生的课堂学习状态和对学习的认识。以往传统的学习都是 偏理论教学, 而行为导向法则更加侧重实践, 通过实践来学习新知识, 学生通过自主思考来完成学习任务。在学生自主学习后, 教师对其学习 成果进行评估, 在实践中有计划的掌握职业技能, 形成完整的知识体系。 从学生的的角度出发, 行为导向法则是围绕机械基础课程展开学习活动, 将学习到的理论与实践进行有机结合, 帮助学生获得更加光明的未来。

\section{2 中职课堂教学存在的问题}

由于中职学生本身学习能力和自身综合素质就有待提高, 中职学生 往往会给教师留下难教、难管的不良印象, 教师与学生都存在一定的主 观刻板印象。中职的学生由于初中阶段学习成绩较差, 缺乏一定的自主 学习能力, 不能很好的的进行自主学习。机械基础课程内容复杂, 存在 一定的难度, 对中职一、二年级的学生来说学习起来并不容易, 课堂学 习中也更多依赖教师的讲解而不会主动动脑思考, 这则是缺乏自主学习 能力的表现, 也是目前中职课堂存在的主要问题。

\section{3 行为导向法培养中职学生机械基础课程自主学习能力的策略}

3.1 提高学生的课堂主体地位

行为导向教学并不存在固定的教学内容, 而是要根据所教授学生的 具体实际情况来实施, 开展这种教学模式首先要提高学生的课堂主体地 位。在课程进行过程中, 学生可以通过行为导向的教学模式, 将自己认 为有价值的问题整理后提出, 将自身的想法和观点表达出来, 提出更加 具有主观性的问题, 然后与教师一起进行讨论, 让学生认识到自己的想 法在课堂中会被得到重视, 从而更加认真的进行思考。例如, 在学习 “螺 纹连接” 内容时, 教师在课程伊始要首先提出教学目标, 在课程结束后, 要求学生对本课所学的内容进行自主整合, 如 “普通螺纹的主要参数、 螺纹的代号标注、螺旋传动的应用形式” 等等。由于机械基础课程中有 许多做图的环节, 学生还应当对所学知识进行做图巩固, 以对螺纹连接 知识掌握的更加透彻。

3.2 活跃课堂的整体气氛

中职一、二年级的学生主要为 00 后的学生, 其对学习内容是否有趣 看的很重要, 只有轻松有趣味性的课堂才能引起他们的注意, 从而会主
动的进行学习。根据这种年龄特征, 教师应当努力活跃起课堂教学氛围, 让学生可以对所学知识感兴趣。如在学习 “联轴器的结构、特点及应用” 知识时, 首先会学习作用 “机械传动中的常见部件, 用来连接两传动轴, 使其一起转动并传递转矩, 有时也可作为安全装置。” 这样的理论内容比 较晦涩难懂, 不容易让学生理解, 教师可以使用比较可爱的卡通模型进 行教学讲解, 不但可以很快吸引学生的注意力, 还可以让学生发现其实 机械课程并不是只有枯燥无味。

3.3 增加课堂中的师生互动

传统的师生关系只是教师负责授课、答疑, 学生负责接收知识。在 行为导向教学法的指导下, 教师可以采用开放式的教学方法, 拉近学生 与教师之间的距离, 鼓励学生勇敢的提出自己的质疑和想法。注重将理 论与实践的结合也是教学的主要任务, 教师可以将学生分成不同的学习 小组, 然后在实际操作中对每个学习小组的学习进度加以关注, 这样既 做到了让每个学生都感受到了教师的关心, 还可以节省教师的课堂答疑 时间。例如, 在学习 “无级变速机构” 时, 学生以小组为单位, 亲自动 手对其进行拆卸和安装, 大家共同进行讨论和探索, 然后各个小组将学 习到的内容进行整合和加工后汇报给教师。在安装、拆卸的过程中, 学 生加深了对变速机构的理解, 会更加主动去探索变速器背后的工作原理, 这样, 学生的主动学习能力就得到了一定程度的增强。在学生进行自行 拆卸过程中, 教师要对每组学生的进度进行实时跟进, 对学生提出的疑 问及时进行解答。如学生普遍会提问的问题教师要对其进行整理, 然后 在课上详细的解答。《机械基础》课程内容生涩难懂, 理论性较强且缺乏 趣味性, 有的学生在没有学明白后不敢向教师进行提问, 导致不会的问 题越堆积越多, 形成恶性循环, 这就需要教师在课上和课下都积极与学 生进行交流, 拉近师生之间的距离。

结合上述分析不难看出, 由于主客观等多种原因, 中职学生的自主 学习能力并不强, 在课堂学习中更多的是依赖教师, 缺乏主动思考的能 力。教师采取行为导向法教学, 可以进一步培养学生主动发现问题并解 决问题的能力, 对学生综合素养的提升起到不可小觑的作用。中职学生 机械基础课程的学习对日后的工作和职业技能考核都有着十分重要的影 响, 作为课堂引导者的教师, 有义务也有责任帮助学生培养起自主学习 意识。

\section{[参考文献]}

[1]朱晓波.用行为导向法培养中职学生机械基础课程的自主学习能 力[J].读与写(教育教学刊),2019.

[2]刘娟,金明辉.行动导向教学法在中职机械基础课程教学中的应用 研究 [J].当代职业教育,2015,000(006):27-29.

[3]郭家彬.行动导向教学法在中职机械基础棵程教学中的应用分析 [J].明日风尚,2018(8). 